\title{
Contributions of the High Frequency Dynamic Wire Feeding in the GTAW Process for Increased Robustness
}

\author{
Regis Henrique Gonçalves e Silva ${ }^{1}$, Rafael Gomes Nunes Silva ${ }^{1}$ (D), Mateus Barancelli Schwedersky ${ }^{1}$, Giovani Dalpiaz $^{2}$, Jair Carlos Dutra ${ }^{1}$ \\ ${ }^{1}$ Universidade Federal de Santa Catarina - UFSC, Instituto de Soldagem e Mecatrônica - LABSOLDA, Departamento de Engenharia Mecânica, Florianópolis, SC, \\ Brasil. \\ 2 Petrobras, Centro de Pesquisa - CENPES, Rio de Janeiro, RJ, Brasil.
}

Como citar: Silva RHG, Silva RGN, Schwedersky MB, Dalpiaz G, Dutra JC. Contributions of the high frequency dynamic wire feeding in the GTAW process for increased robustness. Soldagem \& Inspeção. 2019;24:e2430. https://doi.org/10.1590/0104-9224/SI24.30

\begin{abstract}
The GTAW process is recognized as a process of high metallurgical quality, being widely used in the pipelines welding, mainly in the root pass. The relative independence between the heat delivered to the melting pool and the amount of material added helps to control the melting of the material and to avoid the appearance of welding discontinuities such as lack of fusion and lack ok penetration. When orbital welding is carried out, mainly in the overhead position, there is a tendency of electrode contamination by the melted wire, reducing process productivity and quality. In this scenario, there are some strands of the GTAW process that aim for increased productivity, reconciled with the already present high metallurgical quality. These includes low and high frequency dynamic wire feeding, preheating wire and tangential wire insertion. The present work deals with the contribution of the high frequency dynamic wire feeding for the increase of robustness in the GTAW process, evidencing through voltage monitoring and high speed filming the formation of regular and uniform drops for the process stability.
\end{abstract}

Key-words: TIG; Pulsed wire feeding; Oscillating wire; Automatic GTAW welding.

\section{Introduction}

Although there is a constant seek for improvement for the use of renewable energies, the oil and natural gas industry still represents an indisputable foundation in the world economic-industrial scenario. Not only for energy purposes, the products generated by this industry are used by many sectors of the economy, increasing the requirement for more efficient methods of producing pipelines to transport this comodity [1].

Arc welding is the main manufacturing process used in the construction, repair and maintenance of the pipeline, in order to provide structural integrity of the joints. In addition, more productive welding processes directly influence costs, schedules, analysis risk and project viability.

In the manufacture of pipes, the first step of welding, known as the root pass, is considered as a critical stage in the execution of the pipelines joint, given its structural importance of support for subsequent passes. Typically, the root pass is performed with the GTAW process and filled with the SMAW process, both manual [2], causing difficulty in maintaining the required quality [3-5]. In the orbital welding process, the welding torch is positioned automatically, so that it follows the geometric profile of the tubes to be welded, which remain stationary $[6,7]$.

The GTAW process, while inherently permitting better metallurgical quality when compared to other traditional processes, such as the GMAW process, has a great disadvantage when analyzed for its deposition rate and consequent process productivity [8]. Still, when performed manually, it requires much greater experience and practical knowledge of the operator [9]. As advantages, the GTAW process presents a relatively low equipment cost [10]. The process, because it allows an independence in the rate of material fed with the heat supplied to the workpiece, allows a broad control of the aspects that contribute to a weld with high metallurgical quality, such as penetration control, wettability, dilution, etc. [11].

Due to the presence of a non-consumable electrode near to the addition material molten arc, there is a high tendency and possibility of contamination of this electrode by this molten material. This is critical especially in orbital welding procedures, where the out of position welding is more complex and susceptible to the appearance of defects and contamination of the electrode, because the gravity force acts as to displace the melt pool.

In this scenario, there are modalities of the GTAW process that aim to increase the productivity and robustness of the process. Among these, pre heating wire feeding (Hot Wire) [12,13], tangential wire feed [14] and dynamic wire feed at low [15] and high frequency $[16,17]$ can be mentioned.

There are different options in the automatic wire feeders for the GTAW process that aim to feed at different frequencies, as for dynamic feeding. The present work has the goal of studying the influence of the high frequency dynamic wire feeding in the reduction of electrode contamination tendency by the added wire, and consequently the increase of the process robustness, contributing to the increase of the quality and the reduction of the work time and cost of the process as a whole.

Received: 15 Jul., 2019. Accepted: 14 Oct., 2019.

E-mail: rafaelnunes.mat@hotmail.com (RGNS)

(i) $\$$ This is an Open Access article distributed under the terms of the Creative Commons Attribution Non-Commercial License which permits unrestricted noncommercial use, distribution, and reproduction in any medium provided the original work is properly cited. 


\section{Materials and Equipments}

SAE AISI 1020 steel sheets of 3/8 “ $(9.5 \mathrm{~mm})$ thickness were used for the tests, and the ER 70S- 6 wire-electrode, $1.0 \mathrm{~mm}$ in diameter, was used as the addition material. The workpieces had their surfaces previously cleaned by roughing in order to avoid opening defects and arc instability due to the presence of oxide layers.

The WIG 500i DC Pulse welding source, from Jäckle, was used. This source allows the regulation of current from $5 \mathrm{~A}$ to $500 \mathrm{~A}$, using only constant current for its automatic application, in addition to allowing the approach with preheating wire (Hot Wire), the second not being discussed in the article.

In order to better observe the dynamic aspects of the melt pool during the procedure, the tests were monitored by means of the SAP - Acquisition Systems. The equipment, manufactured by the company IMC Soldagem, allows acquisition of current, voltage, gas flow and wire feeding speed at a sampling frequency of $5 \mathrm{kHz}$.

The voltage measuring channels were installed between the electrode and the workpiece (referred in the work as Arc Voltage), and between the electrode and the wire (referred in the work as Wire Voltage).

In the same way, to increase the understanding of the physical phenomena involved in the process, the IDT MotionPro Y4-S2 high-speed camera was used in conjunction with the IDT data acquisition module to observe details of arc behavior, the electrode, the wire and the melt pool, factors of profound importance for the understanding of the procedures static behavior.

For the goals aimed in this work, a welding wire feeder was adopted that allows continuous and dynamic wire feeding at high frequency, in a frequency of $18 \mathrm{~Hz}$. Figure 1 shows the sketch of the equipment device for the welding tests.

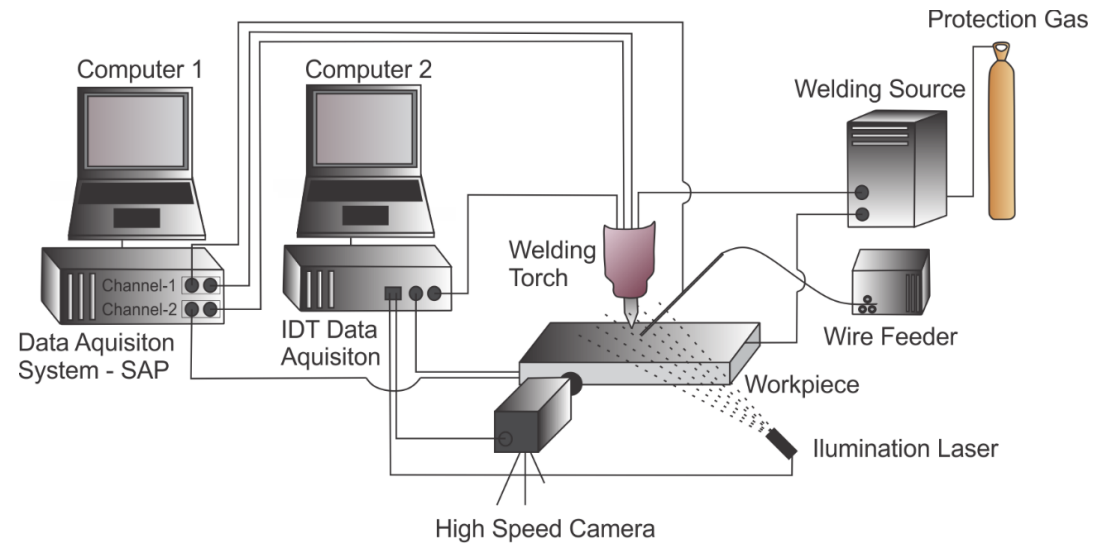

Figure 1. Sketch of experimental device.

The wire feeding was performed in front of the arc, with a distance of $4.8 \mathrm{~mm}$ between the electrode and the added wire.

\section{Experimental Procedure}

As the main goal of the work is to evaluate dynamic wire feeding on the robustness of the process, electronic parameters were set, listed in Table 1, changing only the dynamic feed forms, with an oscillation frequency of $18 \mathrm{~Hz}$, and continuous (0 Hz).

Table 1. Parameters used for the execution of the welding processes with continuous and high frequency dynamic wire feeding.

\begin{tabular}{cc}
\hline Arc Current (A) & 150 \\
Welding Speed (cm/min) & 20 \\
Wire Feed Speed (m/min) & 1.5 \\
Dynamic Wire Feed Frequency (Hz) & 18 \\
Electrode Composition & $98 \%$ W $2 \%$ Ce \\
Electrode Diameter (mm) & 3.2 \\
Electrode Angle (o) & 45 \\
Wire Material & ER 70S-6 \\
Wire Diameter (mm) & 3.2 \\
Base Material Composition & SAE AISI 1020 \\
Base Material Thickness (mm) & 9.5 \\
Protection Gas & Ar \\
Gas Flow Protection (l/min) & 12 \\
Distance Between Electrode and Base Material (mm) & 4.0 \\
\hline
\end{tabular}

*Only valid for procedures that use the dynamic wire feed. 
Thus, three replicates were performed for each of the scenarios analyzed.

Given the importance of understanding the real influence of dynamic wire feed at high frequency, a more detailed approach was required in the wire feed motion. In order to evaluate this behavior, high speed filming was carried out during the welding process (Figure 2).

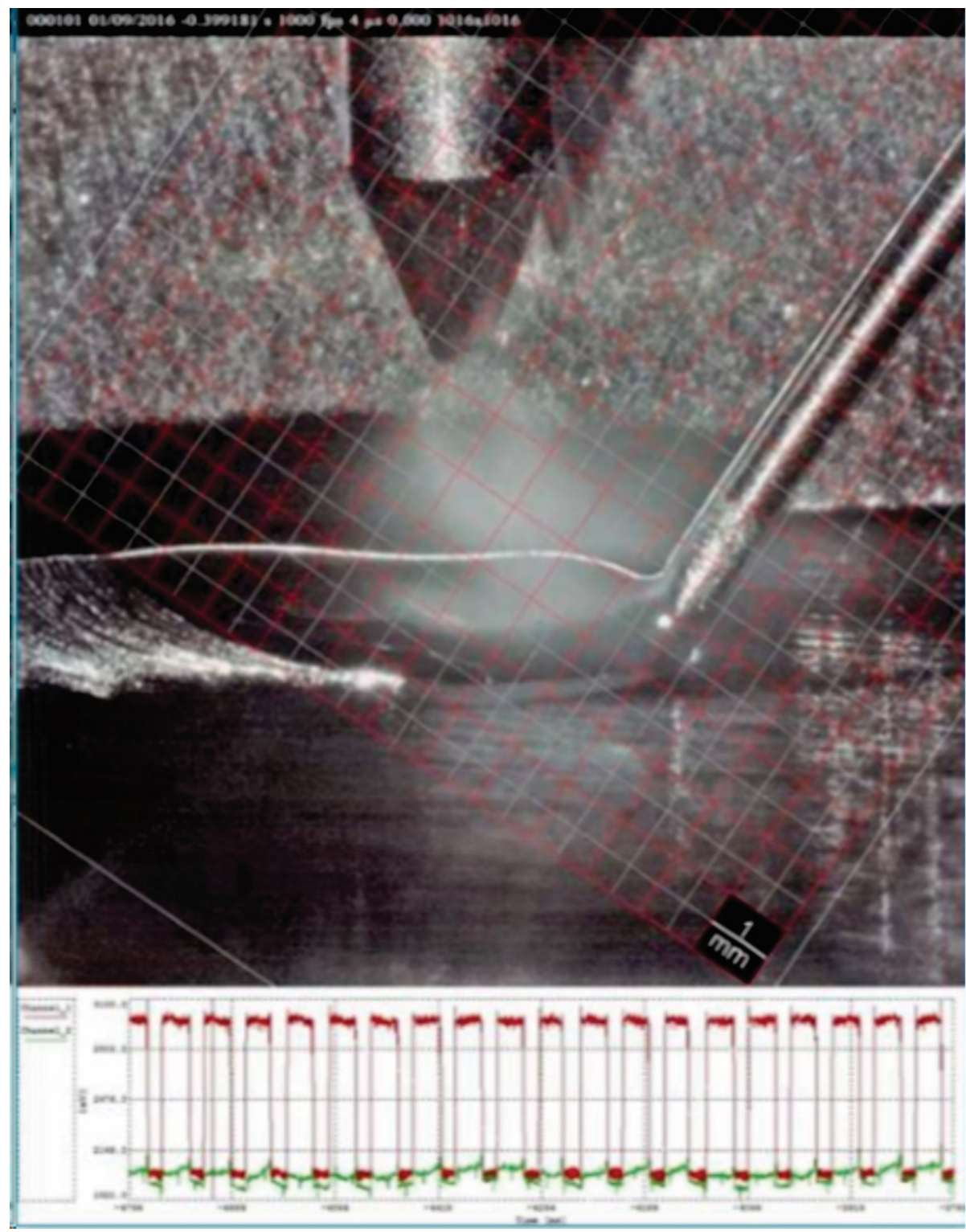

Figure 2. High speed filming for analysis of instantaneous speed and wire feeding period [18]

\section{Results and Discussion}

From the analysis of the high speed filming, it was possible to measure the instantaneous wire feed rates during the advance and stopped period. For the parameterized wire speed of $1.5 \mathrm{~m} / \mathrm{min}$ (set speed), it was found that the actual wire feed rates in the wire torch, at the moments of wire forward movement, averaged $10.7 \mathrm{~m} / \mathrm{min}$. This measured average speed value is due to the short period in which the wire remains in forward movement as compared to the time it remains stopped. While the wire is stopped for $44 \mathrm{~ms}$ at each oscillation period, it is in forward motion for only $7 \mathrm{~ms}$.

During the welding tests, the data acquisition via SAP becomes necessary, as already mentioned, for a deeper analysis and understanding of the electronic phenomena and their physical consequences that are occurring in the arc and in the melt pool.

This way, factors such as the period of detachment and the dynamic behavior of the electric arc can be evaluated.

In tests conducted with continuous wire feeding, a lack of periodicity can be easily observed in the periods where the wire is detached from the melting pool (Figure 3). This fact is justified by the lower instantaneous speed of wire feed, making it more susceptible to the thermal influence of the electric arc, whereby a large droplet is formed, followed by its detachment due to 
the surface tension from the weld pool. Due to the heterogeneity of the droplet size, caused by the randomness of its mechanical oscillation and that of the pool until it touches the weld pool, the detachment time is also heterogeneous.

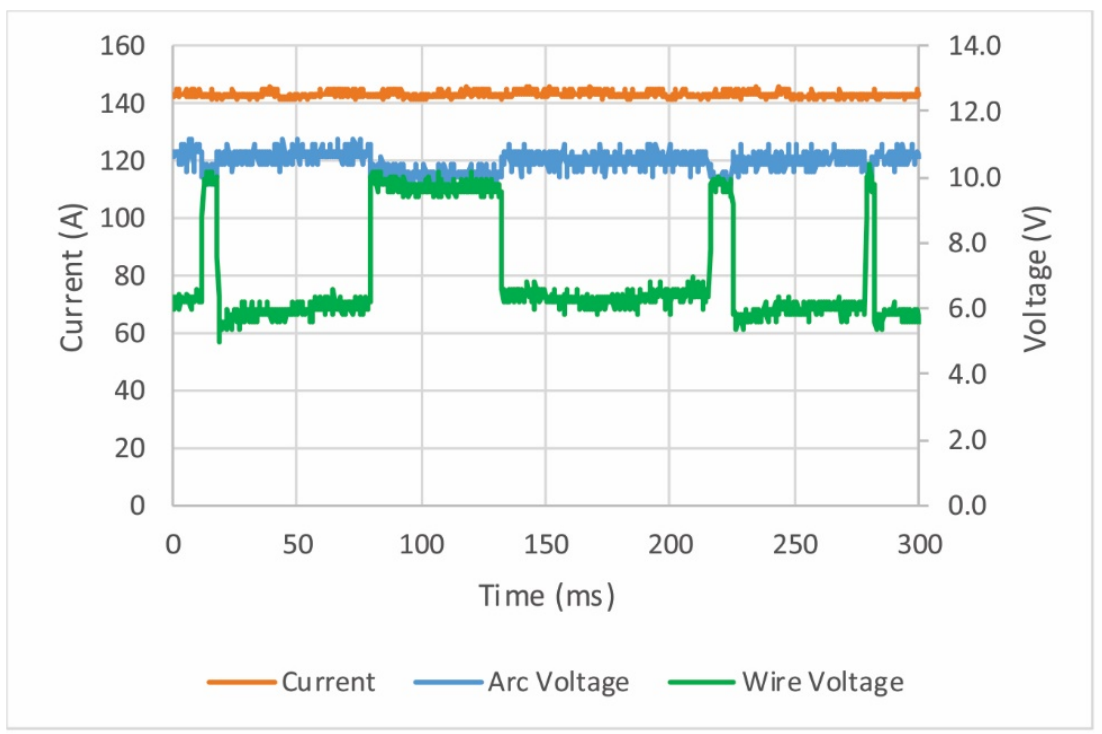

Figure 3. Acquisition of procedure data using continuous wire feeding.

Analogously, the wire detachment profile of the procedures performed with high frequency dynamic wire feeding (Figure 4) can be analyzed.

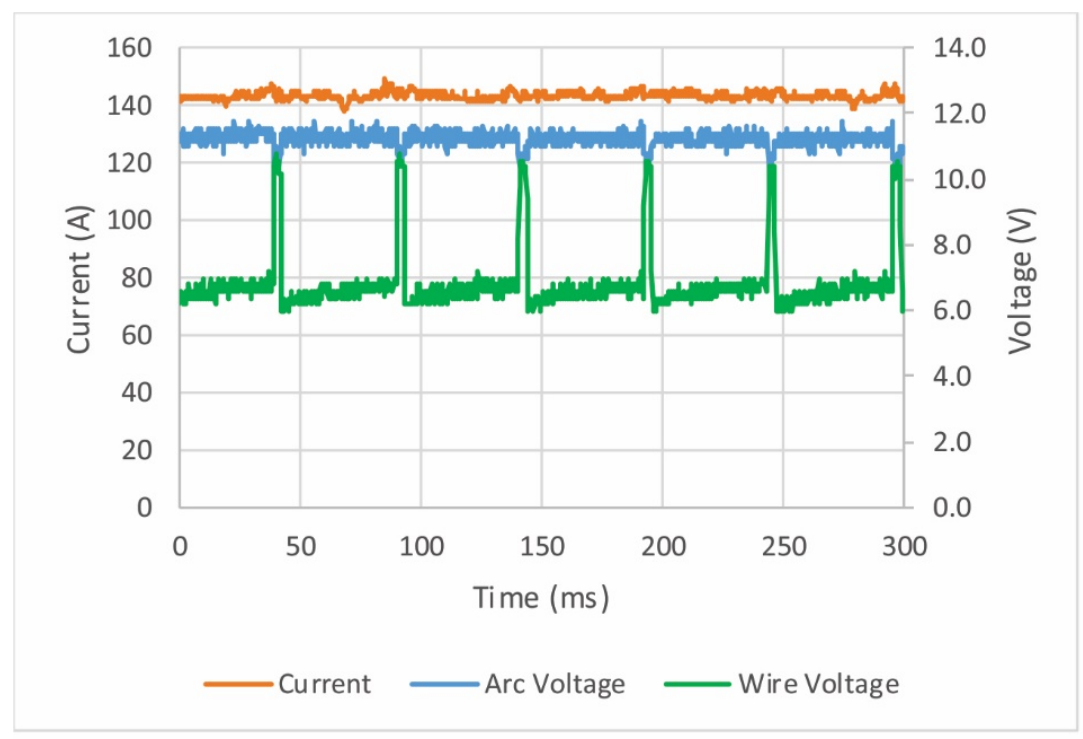

Figure 4. Acquisition of procedure data using high frequency dynamic wire feeding.

In the tests carried out with high frequency dynamic wire feeding, a regular, homogeneous droplet detachment profile can be observed, supporting the fact that the dynamic wire feeding assists in the formation of periodic and regular cycles in the formation and detachment of drops. This is due to the high instantaneous forward speed, which allows only for a small droplet to be formed, whose detachment is then governed by the retraction or stall of the wire, in a periodic fashion.

The electric data profiles of the performed procedures support the construction of the theory of this work, in the sense of increasing the robustness of the GTAW process with high frequency dynamic wire feeding. However, only with high speed filming is it possible to understand and assess the observed behavior.

The variation of both measured voltage signals observed by the data acquisition proves to be a mechanical disturbance of the electric arc. When the wire is in contact with the melt pool (Figure 5B), the arc is anchored closer to the wire, due to the 
formation of a smaller minimum distance between the two electrodes of the system, unlike the moment when the wire is detached from the melt pool (Figure 5A).
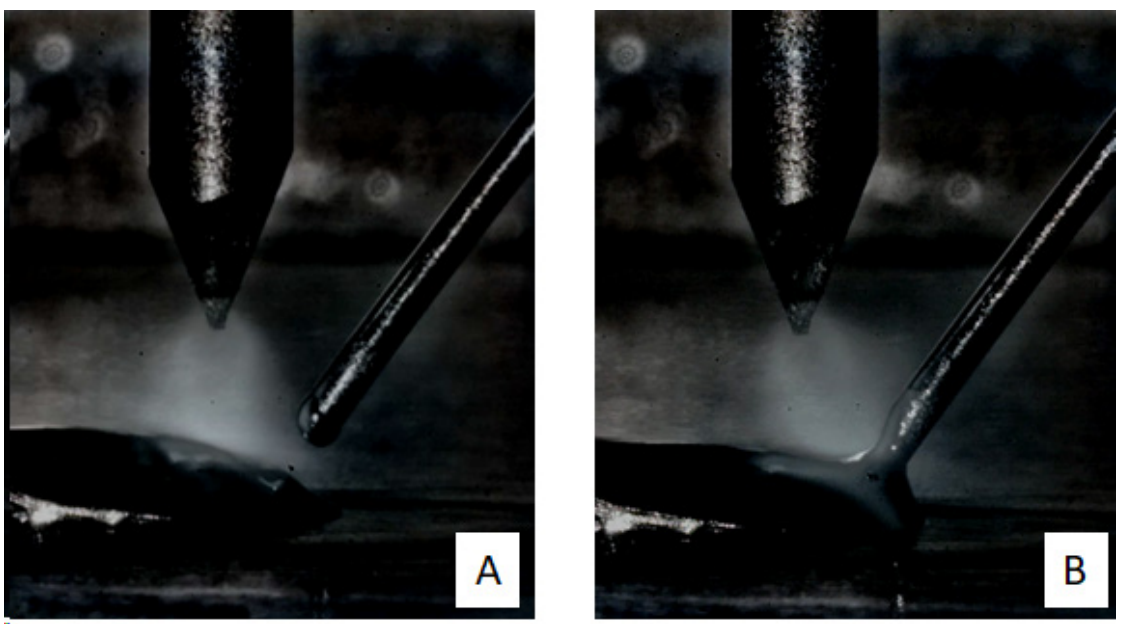

Figure 5. High speed filming of the welding procedure with dynamic wire feeding, at times with detachment $(A)$ and anchoring $(B)$ of the wire in the melt pool [19].

This perturbation can be better observed by joining the two moments analyzed above (Figure 6).

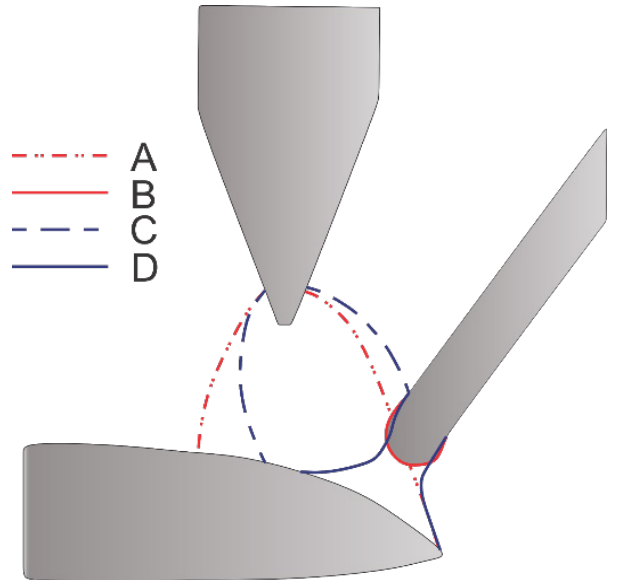

Figure 6. Analysis of the disturbance behavior of the arc during the detachment and anchoring of the wire from the melt pool. (A) Profile of the electric arc with the detached wire; (B) Detached wire profile; (C) Profile of the electric arc with the wire anchored in the met pool; (D) Anchored wire profile.

Figure 6 illustrates the morphological difference of the electric arc between the moments where the wire is in contact (A) and detached (C) from the melt pool. Captions (B) and (D) correspond to the profile of the wire while it is in contact and detached from the melt pool, respectively.

The perturbation of the arc caused by the detachment and anchoring of the wire in the melting pool, is reflected in the variation of the instantaneous average voltage (Figure 7). 


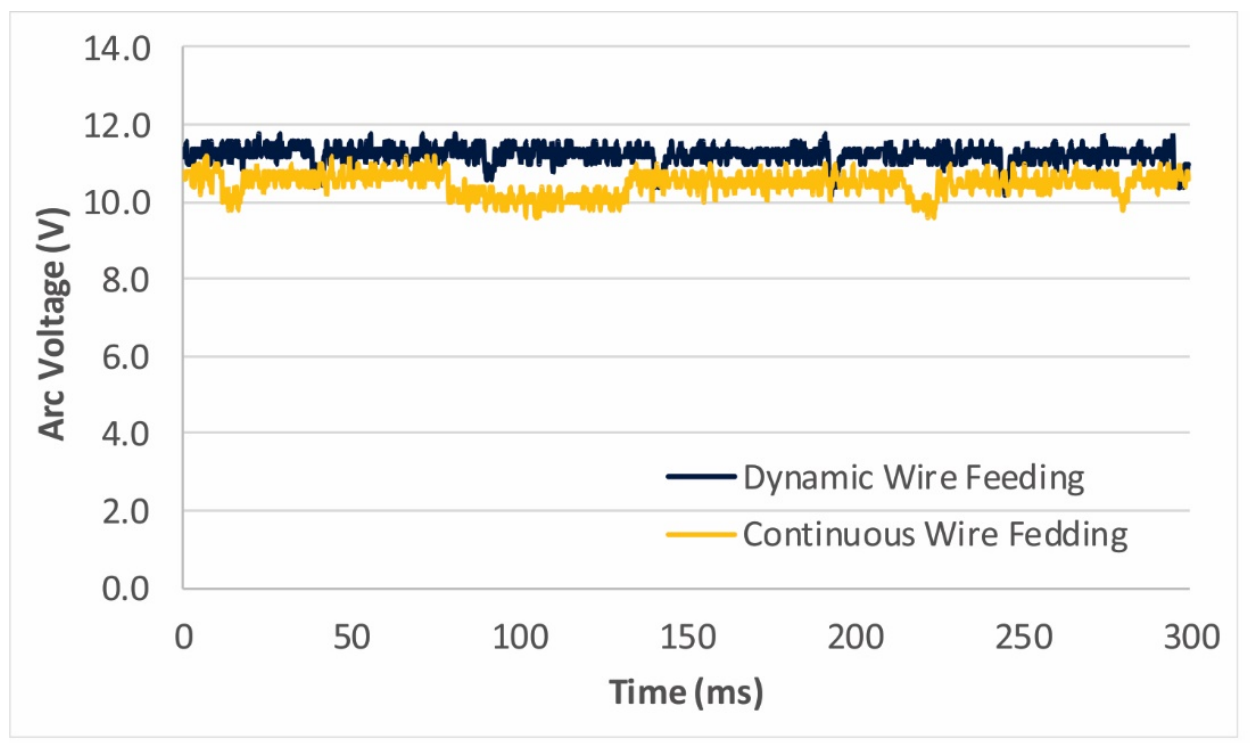

Figure 7. Average arc voltage of the continuous and dynamic wire feeding.

Similarly, through the direct relation between power and voltage (Equation 1), the same occurs in the variation of the average power of the evaluated procedures (Figure 8).

$P=U^{*} I$

where $P$ is the arc power, $U$ is the arc voltage, and $I$ is the arc current.

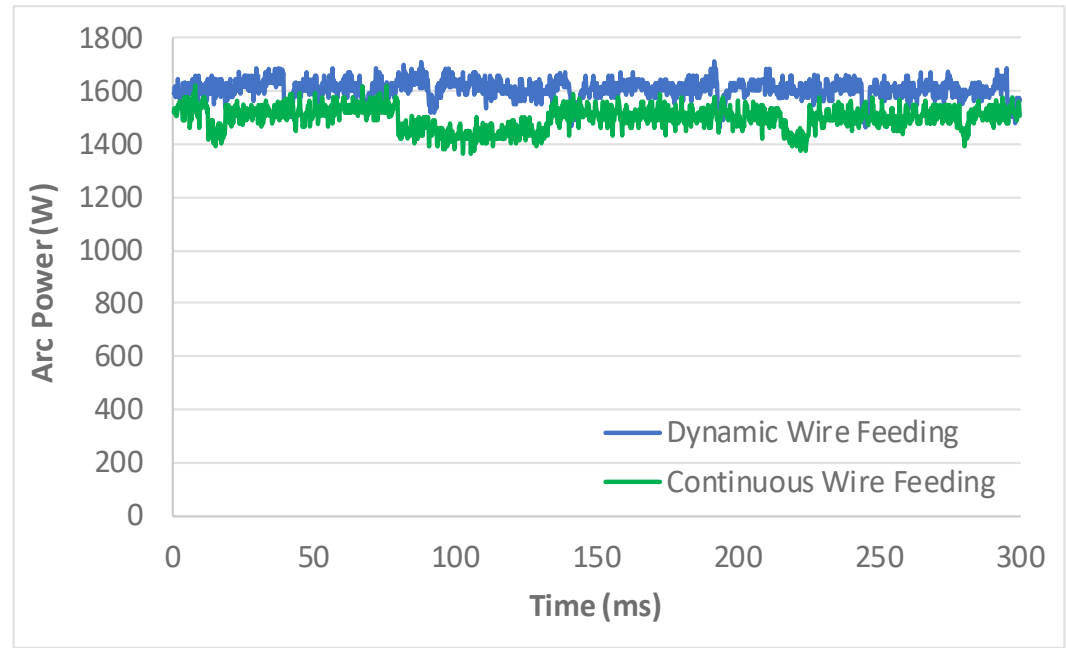

Figure 8. Average arc power of the continuous and dynamic wire feeding.

Based on the static behavior of the two procedures, the total average arc voltage and the total average arc power (Table 2) were calculated. Given a period large enough to allow a satisfactory number of repetitions of the wire detachment cycle for both processes, the influence of dynamic wire feed on the process power is evident.

Table 2. Total average arc power and average arc voltage obtained for the continuous and dynamic wire feeding procedures.

\begin{tabular}{ccc}
\hline & Average Arc Power (W) & Average Arc Voltage (V) \\
Dynamic Wire Feeding & 1609 & 11.2 \\
Continuous Wire Feeding & 1499 & 10.5 \\
\hline
\end{tabular}


While the process with dynamic wire feed presented an average arc power of $1609 \mathrm{~W}$, with a very stable and homogeneous pattern, the continuous wire feed process had an average arc power of $1499 \mathrm{~W}$, with a comparatively heterogeneous pattern. This variability can be further analyzed through the histograms in Figure 9.

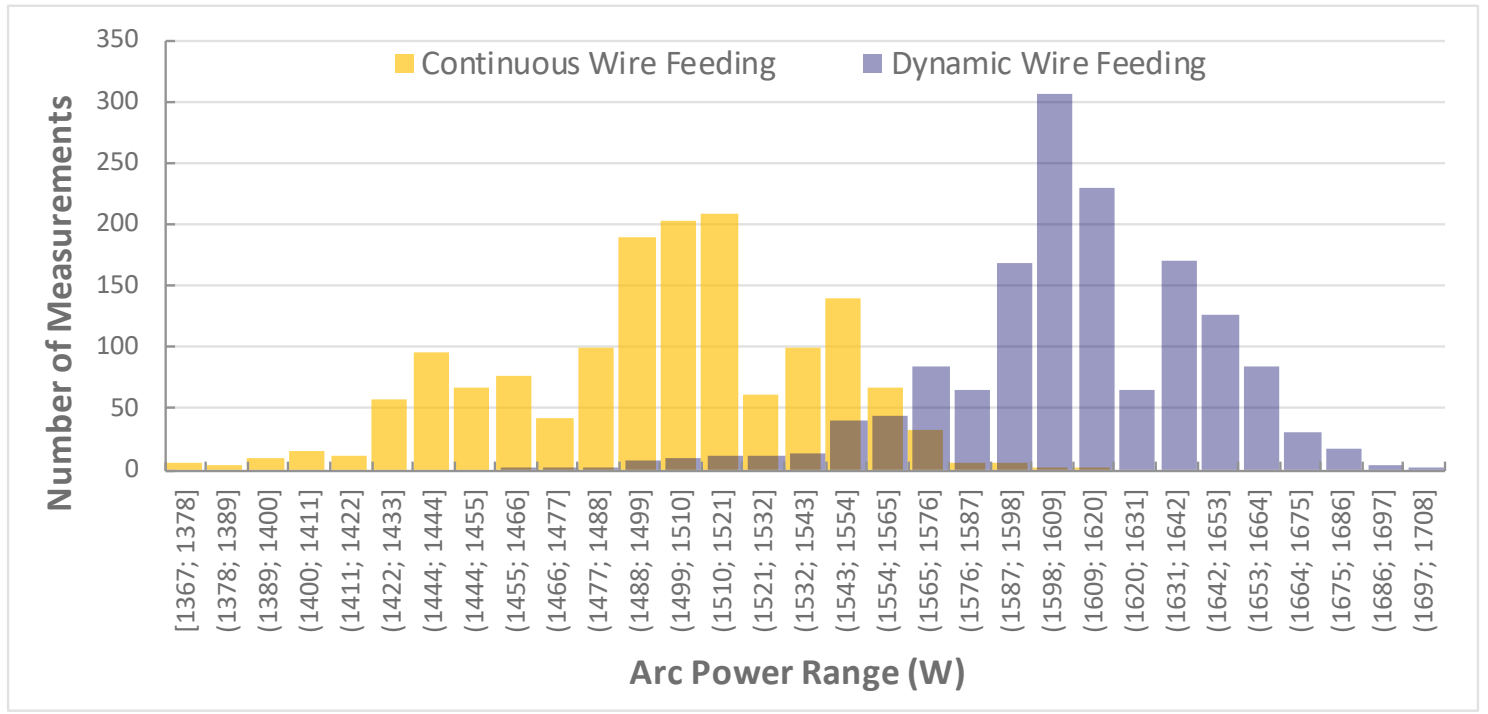

Figure 9. Histograms of the average arc power continuous and dynamic wire feeding GTAW Welding.

The formation and detachment of non-uniform and inconstant droplets has as main consequences the formation of coarse droplets which, due to their high volume and mass, can compromise the execution of the repeatability of the process and the electrode used. These aspects were observed using continuous wire feeding (Figure 10).
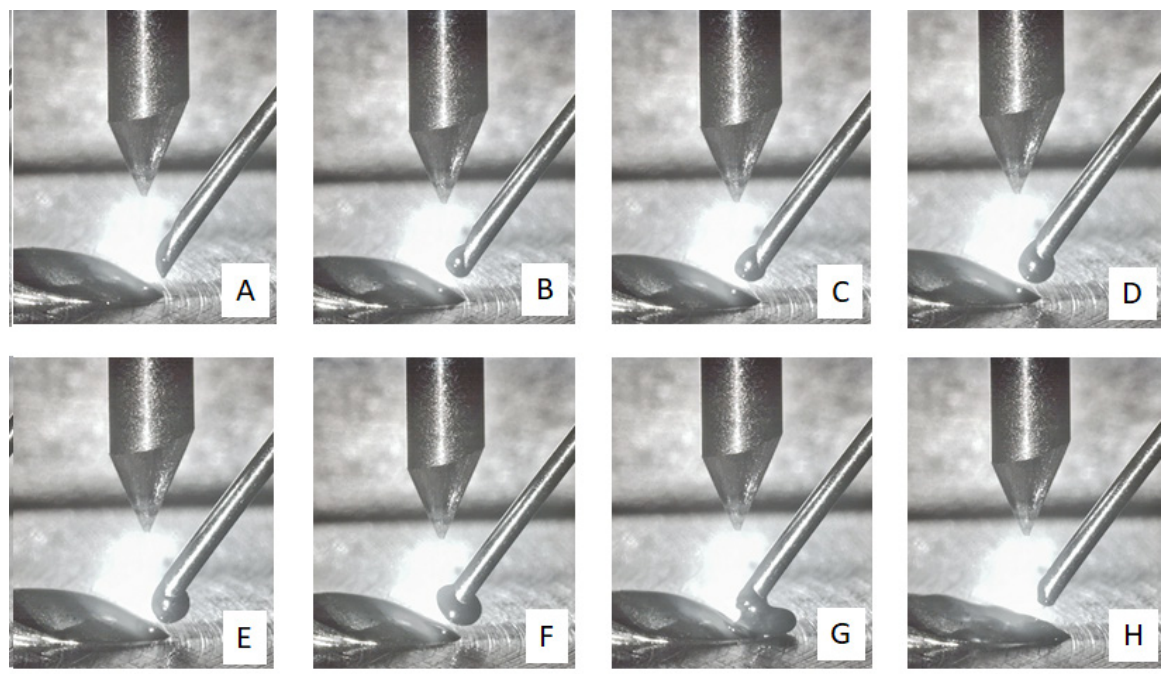

Figure 10. Formation behavior and detachment of droplet in the process performed with continuous wire feeding. (A-F) Formation of the coarse drop; (G) Coarse drop contact with material and base and detachment; (H) Cycle restart [20].

In the high speed filming of the process with continuous wire feeding, the formation of coarse drops, with an average volume of $2.14 \mathrm{~mm}^{3}$, can be observed, compromising the integrity of the process.

In the procedure with the use of high frequency dynamic wire feeding, the wire, due to its high instantaneous speed of advance, does not suffer as much influence of the electric arc heat, arriving at the melt pool with a smaller liquid region when compared to the process with continuous wire feeding, as show in Figure 11. The average volume of the droplets formed for the dynamic wire feeding process was measured at $0.63 \mathrm{~mm}^{3}$, approximately 3 times lower than the droplets formed from the continuous feed process. 

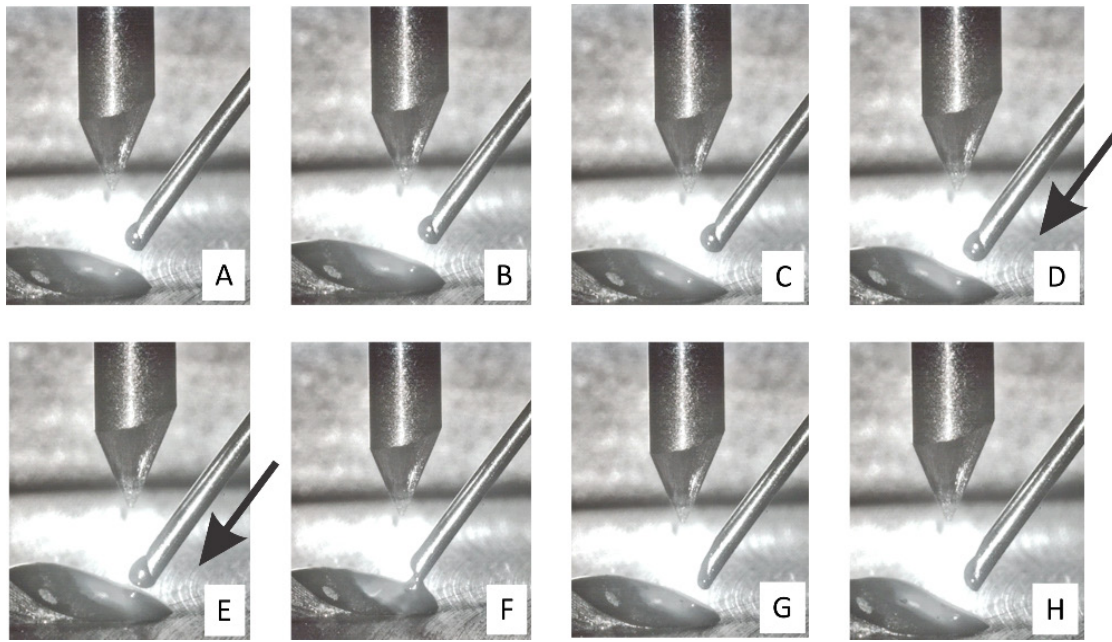

Figure 11. Behavior of formation and detachment of droplet in the process realized with high frequency dynamic wire feeding. (A-C) Gout formation; (D-E) Moving Wire; (F) Drop contact with the melt pool and detachment; (G-H) Cycle restart [21].

Finally, forced welding tests were carried out, with the intention of reaching the approximation limit between the electrode and wire and observing the tendency of contamination of the electrode in the two scenarios, with continuous wire feeding and high frequency dynamic wire feeding.

While the tests performed with dynamic wire feeding presented satisfactory results of repetition and exemption of electrode contamination, the tests performed with continuous wire feeding presented very different and unsatisfactory results, as can be observed in Figure 12 .
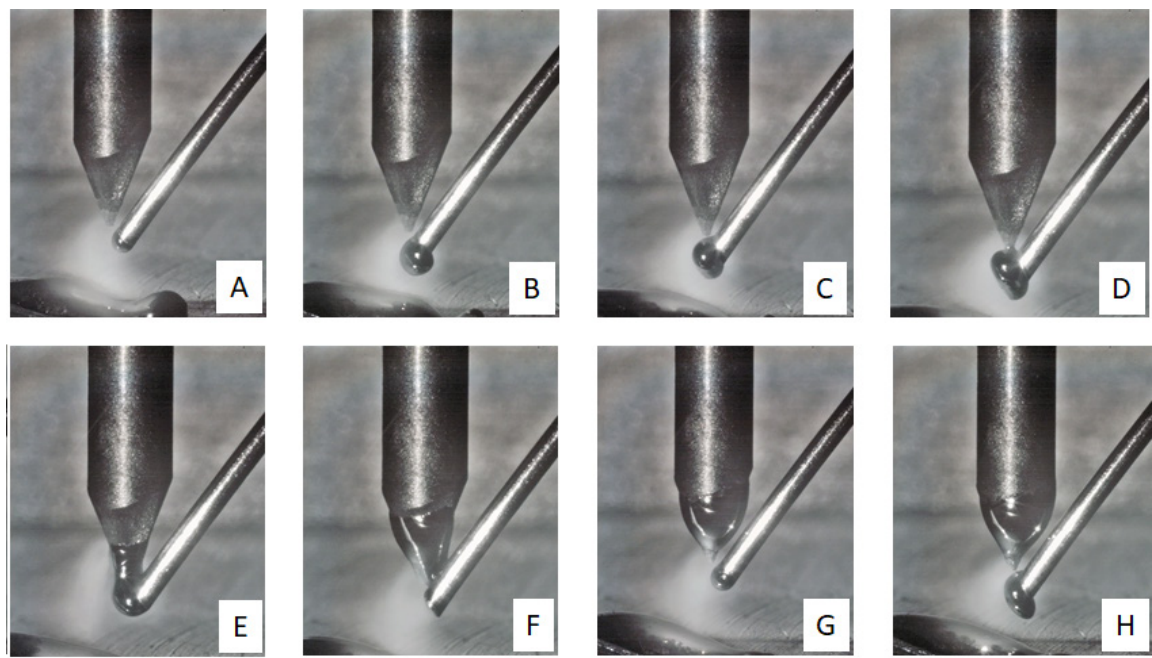

Figure 12. Formation behavior and detachment of droplet in the process performed with continuous wire feeding. (A-C) Coarse droplet formation; (D-F) Contact of the coarse drop with the tungsten electrode; (G) Detachment of the coarse drop for the tungsten electrode;

(H) Formation of a new coarse drop [22].

Through this test, the robustness of the process proposed by the high frequency dynamic wire feeding has been proven, achieving satisfactory repeatability and electrode integrity during the process.

\section{Conclusions}

The huge difference between the instantaneous wire feed rate during the forward movement in dynamic wire feed $(10.7 \mathrm{~m} / \mathrm{min}$ forward speed, for an average set speed of $1.5 \mathrm{~m} / \mathrm{min}$ ) and the average set speed parameterized for continuous feed $(1.5 \mathrm{~m} / \mathrm{min})$ are responsible for the distinguishing features of dynamic wire feeding. The higher instantaneous wire feed speed implies in a shorter period of time in which the wire is subjected to the electric arc heat.

Due to this aspect, one can understand the absence of the tendency of coarse droplets to form during the dynamic feed process. The formation of droplets and its consequent detachment becomes more uniform, regular and homogeneous, which can be observed and concluded from the analysis of arc voltage and power of the processes with continuous and dynamic wire 
feeding. Thus, the process benefits not only from the more regular electric behavior, and consequent more regular heat input to the piece, but also from the higher robustness against instabilities caused by electrode contamination.

\section{References}

[1] Sartori F, Silva RHG, Dutra JC, Paes LES, Schwedersky MB, Marques C. Uma análise comparativa entre diferentes versões de variantes modernas do processo MIG/MAG para o passe de raiz em soldagem orbital. Soldagem e Inspeção. 2017;22(4):442-452. http://dx.doi.org/10.1590/0104-9224/si2204.04.

[2] Emmerson JG. FCAW orbital pipe welding technology improves fab shop productivity. Welding Journal. 1999;78(11):57-59.

[3] Fronius International GmbH. Orbital welding facts. Vol. 2. Wels: Polysoude Nantes Frankreich SAS; 2010. 52 p.

[4] Samardzic I, Despotovic B, Klaric S. Automatic pipe butt welding processes in steam boiler production. Welding in the World. 2007;51(7):615-624.

[5] Garcia JAO, Dias NS, Lima GL, Pereira WDB, Nogueira NF. Advances of orbital gas tungsten arc welding for Brazilian space applications experimental setup. Journal of Aerospace Technology and Management. 2010;2(2):211-218. http://dx.doi.org/10.5028/jatm.2010.02026610.

[6] Lukkari J. Orbital-TIG - a great way to join pipes. ESAB Welding and Cutting Journal. 2005;60(1):3-6.

[7] Cunha TV, Dutra JC. Desenvolvimento de um sistema de soldagem orbital de tubos: concepção do equipamento. In: Associação Brasileira de P\&D em Petróleo e Gás. Anais do $4^{\circ}$ Congresso Brasileiro de Pesquisa e Desenvolvimento em Petróleo e Gás; 2007 Outubro 21-14; Campinas, Brazil. Campinas: Associação Brasileira de P\&D em Petróleo e Gás; 2007.

[8] Vilarinho LO, Kumar V, Lucas B, Raghunathan S. Successful High-Productivity Welding with A-TIG PROCESS. In: Proceedings of COBEM; 2009; Gramado, RS, Brasil. São Paulo: ABCM; 2009.

[9] Singh AK, Dey V, Rai RN. Techniques to improveweld penetration in TIG welding (a review). Materialstoday: proceedings, 2017;4(2):1252-1259. https://doi.org/10.1016/j.matpr.2017.01.145.

[10] Chen JS, Chen J, Zhang K, Feng Z, Zhang YM. Dynamic reflection behaviors of weld pool surface in pulsed GTAW. Welding Journal. 2018;97(6):191s-206s. http://dx.doi.org/10.29391/2018.97.017.

[11] Sivachidambaram P, Balachandar K. Studies the influence of pulsed current and activated flux with TIG welding on the microstructure and mechanical properties of stircasted Al-SiC composite. Indian Journal of Science and Technology. 2015;8(27):1-6. http://dx.doi.org/10.17485/ijst/2015/v8i27/71559.

[12] Hori, K., Watanabe, H., Myoga, T., Kusano, K. Development of hot wire tig welding methods using pulsed current to heat filler wireresearch on pulse heated hot wire tig welding processes. Welding International 2004;18(6):456-468. http://dx.doi.org/10.1533/wint.2004.3281.

[13]Silwal B., Santangelo M. Effect ofvibration and hot-wire gas tungsten arc (GTA) on the geometric shape. Journal of Materials Process Technology 251:138-145. 2018. https://doi.org/10.1016/J.JMATPROTEC.2017.08.010.

[14] Godinho C, Silva RHG, Schwdersky MB. Estudo comparativo entre a injeção tangencial e radial de arame do processo TIG. In: Anais do XLII Consolda - Congresso Nacional de Soldagem; 2016; Belo Horizonte, MG, Brasil. São Paulo: ABS; 2016.

[15] Silva RHG, Paes LES, Okuyama MP, Sousa GL, Viviani AB, Cirino LM, et al. TIG welding process with dynamic feeding: a characterization approach. International Journal of Advanced Manufacturing Technology. 2018;96(9-12):4467-4475. http://dx.doi.org/10.1007/s00170018-1929-6.

[16] Silva RHG, Correa Riffel K, Pompermaier Okuyama M, Dalpiaz G. Effect of dynamic wire in the GTAW process. Journal of Materials Processing Technology. 2019;269:91-101. http://dx.doi.org/10.1016/j.jmatprotec.2019.01.033.

[17] Wilson M. TIP TIG: new technology for welding. Industrial Robot: an International Journal. 2007;34(6):462-466. http://dx.doi.org/10.1108/01439910710832057.

[18] Instituto de Soldagem e Mecatrônica - LABSOLDA. Período e velocidade de alimentação de arame em soldagem TIG com alimentação dinâmica [video]. 2019 May 16 [access 10 july 2019]. Available from: https://www.youtube.com/watch?v=mPtsUI5J9xg\&feature=youtu.be

[19] Instituto de Soldagem e Mecatrônica - LABSOLDA. Formação de gotas regulares e uniformes em soldagem TIG com alimentação dinâmica de arame [video]. 2019 May 16 [access 10 july 2019]. Available from: https://www.youtube.com/watch?v=jxQUGA1BIZ8\&feature=youtu.be

[20] Instituto de Soldagem e Mecatrônica - LABSOLDA. Formação de gotas irregulares e não uniformes em soldagem TIG com alimentação contínua de arame [video]. 2019 May 16 [access 10 july 2019]. Available from: https://www.youtube.com/watch?v=NAFV_YfldC4\&feature=youtu.be 
[21] Instituto de Soldagem e Mecatrônica - LABSOLDA. Formação de gotas regulares e uniformes em soldagem TIG com alimentação dinâmica de arame [video]. 2019 May 16 [access 10 july 2019]. Available from: https://www.youtube.com/watch?v=jxQUGA1BIZ8\&feature=youtu.be

[22] Instituto de Soldagem e Mecatrônica - LABSOLDA. Análise da contaminação do eletrodo pelo arame de adição no processo de soldagem TIG [video]. 2019 May 16 [access 10 july 2019]. Available from: https://www.youtube.com/watch?v=GVUWbd7NcRQ\&feature=youtu.be 